Article

\title{
Plant Growth Promoting Effects of Nepalese Sweet Potato Endophytes
}

\author{
Sabitri Adhikari Dhungana ${ }^{1,2}$, Fumihiko Adachi ${ }^{3}$, Shohei Hayashi ${ }^{3}$, Ramesh Raj Puri ${ }^{1}$ \\ and Kazuhito Itoh $1,3, *$ (iD \\ 1 The United Graduate School of Agricultural Sciences, Tottori University, 4-101 Koyama-Minami, \\ Tottori 680-8553, Japan; sabitriko@gmail.com (S.A.D.); rameshrajpuri@gmail.com (R.R.P.) \\ 2 Nepal Agricultural Research Council, Singhadurbar Plaza, Kathmandu 44600, Nepal \\ 3 Faculty of Life and Environmental Sciences, Shimane University, 1060 Nishikawatsu, Matsue, \\ Shimane 690-8504, Japan; fadachi@life.shimane-u.ac.jp (F.A.); shohaya@life.shimane-u.ac.jp (S.H.) \\ * Corresponding: itohkz@life.shimane-u.ac.jp; Tel.: +81-852-32-6521
}

Received: 11 October 2018; Accepted: 30 November 2018; Published: 6 December 2018

\begin{abstract}
Endophytic bacteria form a symbiotic relation with plants and generally cause no harmful effects to the host plants. In a previous study, we isolated eight bacterial endophytes from sweet potato plants harvested in Salyan, Nepal. These endophytes showed plant growth-promoting properties as a mixed culture. In this study, we evaluated the ability of these strains to produce indole-3-acetic acid (IAA) and to fix nitrogen. Based on these results, we selected two strains, Klebsiella sp. Sal 1 and Enterobacter sp. Sal 3, and evaluated their ability to promote plant growth. IAA production activity peaked at $15-60 \mathrm{mg} \mathrm{NH} \mathrm{NO}_{3} / \mathrm{L}$ in plant-free medium. Similarly, acetylene reduction activity peaked at 0-6.25 $\mathrm{mg} \mathrm{NH}_{4} \mathrm{NO}_{3}$ /L. Both strains successfully colonized plants, promoted the growth of tomatoes, and induced phenotypes in plants consistent with IAA exposure. This suggests that these strains promote plant growth by producing IAA inside the plant, where nitrogen levels are expected to be low.
\end{abstract}

Keywords: endophyte; indole-3-acetic acid (IAA); sweet potato; tomato; nitrogen fixation; colonization

\section{Introduction}

Endophytic bacteria colonize the internal tissue of the host plant, forming a symbiotic relationship without detrimental effects to the tissue of most plants [1,2]. Many plant growth-promoting endophytes can fix nitrogen, produce phytohormones, and express 1-aminocyclopropane-1-carboxylate (ACC) deaminase [3-5].

Sweet potato (Ipomoea batatas, L.) is cultivated in several countries in Asia, Africa, Europe, and America. This plant can be cultivated with little fertilization [6,7], probably due to its association with endophytes [8] and a general behavior/response of sweet potato as a plant species. For example, sweet potato endophytes Bacillus cereus, Achromobacter xylosoxidans, and Rahnella aquatilis showed superior indole-3-acetic acid (IAA) production and phosphate solubilizing abilities, which may improve the nutrient uptake, root growth, and overall plant growth $[9,10]$.

However several plants and soil types may lack the efficient endophytes that have superior plant growth-promoting activities. Therefore, the isolation and inoculation of plant growth-promoting endophytes can contribute to economically efficient crop production systems by reducing the use of chemical fertilizers or pesticides [11].

Nepal is a small Himalayan country with a high degree of biodiversity. The diverse climates and soils of Nepal produce favorable conditions for high microbial diversity, including microbes such as legume-nodulating bacteria [12,13]. However, there are limited reports on endophytic bacteria in 
Nepal. Venkatachalam et al. [14] reported a diverse bacterial community in temperate soils of Nepal with different enzymatic activities. In our previous study, we reported diverse genotypes of sweet potato bacterial endophytes in 12 different locations in Nepal, and the inoculation of mixed cultures of the strains from each location improved the fresh weight and vine length of sweet potato in growth chambers [15]. In this study, the endophytes from the 'Salyan' location were selected based on their physiological and plant growth-promoting properties to identify endophytes that can promote plant growth. As the effects of nitrogen levels on plant growth-promoting properties of endophytes have not been extensively examined yet, IAA production and nitrogen fixation activities were examined at different levels of nitrogen in this study. Plant growth promotion by the endophytes was also examined using sweet potato as a host plant. Tomatoes were also used due to their sensitive response to inorganic nitrogen levels and preparation of uniform seedlings from seeds.

\section{Materials and Methods}

\subsection{Bacterial Strains}

Strains used in this study were isolated from Nepalese sweet potato tubers [15]. Eight sweet potato endophytes from the Salyan location were used in this study (Table 1).

Table 1. Endophytes used in this study isolated from sweet potato cultivated in Salyan, Nepal.

\begin{tabular}{cccc}
\hline Strain & * Most Similar Genus & Class & Accession Number \\
\hline Sal 1 & Klebsiella sp. & Gammaproteobacteria & LC389410 \\
Sal 2 & Flavobacterium sp. & Flavobacteriia & LC389415 \\
Sal 3 & Enterobacter sp. & Gammaproteobacteria & LC389433 \\
Sal 4 & Rhizobium sp. & Alphaproteobacteria & LC389434 \\
Sal 5 & Stenotrophomonas sp. & Gammaproteobacteria & LC389439 \\
Sal 6 & Herbasprillum sp. & Betaproteobacteria & LC389442 \\
Sal 7 & Agrobacterium sp. & Alphaproteobacteria & LC389443 \\
Sal 8 & Microbacterium sp. & Actinobacteria & LC389445 \\
\hline \multicolumn{4}{c}{}
\end{tabular}

\subsection{Evaluation of Plant Growth Promoting Properties}

\subsubsection{IAA Production}

The ability of the selected eight endophytes to produce IAA was determined following the Salkowski assay [16]. Strains were grown in Modified Rannie (MR) [17] liquid medium amended with $\mathrm{NH}_{4} \mathrm{NO}_{3}$ at $0.1 \mathrm{~g} / \mathrm{L}(\mathrm{N}+\mathrm{MR})$ and $200 \mu \mathrm{g} / \mathrm{mL}$ tryptophan, and incubated at $26^{\circ} \mathrm{C}$ at $150 \mathrm{rpm}$. Samples without inoculation were set as the control. After 3 days of incubation, an aliquot of the supernatant was taken after centrifugation at $10,000 \times g$ for $10 \mathrm{~min}$ at $4{ }^{\circ} \mathrm{C}$. Then, a double volume of Salkowski reagent was added, and the absorbance was measured at $530 \mathrm{~nm}$ using a UV-VIS spectrophotometer (UV-1700, Shimadzu, Kyoto, Japan) after 30 min in darkness.

The potential of Klebsiella sp. Sal 1 and Enterobacter sp. Sal 3, which showed higher activity, was also examined in $\frac{1}{2}$ MS plant growth medium [18] (in which the amount of macroelement was adjusted to $1 / 2$ strength) with sucrose and tryptophan levels at $0.87 \mathrm{~g} / \mathrm{L}$ and $200 \mu \mathrm{g} / \mathrm{mL}$, respectively. IAA production was also measured at ammonium nitrate levels of $0,0.015,0.03,0.24,0.48$, and $1.2 \mathrm{~g} / \mathrm{L}$.

\subsubsection{Nitrogen Fixation Activity}

For Klebsiella sp. Sal 1 and Herbaspirillum sp. Sal 6, which were reported to have the nif H gene [15], the acetylene reduction assay (ARA) was conducted. Cell suspensions of the isolates were prepared at $10^{9} \mathrm{CFU} / \mathrm{mL}$ after 2 days of culture in liquid MR medium and then washed twice with autoclaved distilled water by centrifugation (at $10,000 \mathrm{rpm}$ at $4{ }^{\circ} \mathrm{C}$ for $10 \mathrm{~min}$ ). A $50 \mu \mathrm{L}$ aliquot of the cell suspension was poured over a slant of MR agar $(1.1 \%)$ medium in a $121 \mathrm{~mL}$ glass bottle containing 
different levels of nitrogen $\left(\mathrm{NH}_{4} \mathrm{NO}_{3} ; 0,6.25,12.5,25,50,75,100 \mathrm{mg} / \mathrm{L}\right)$. The bottle was capped, and $10 \%$ of the air inside the bottle was replaced by acetylene gas and then incubated in darkness at approximately $30^{\circ} \mathrm{C}$ for 4 days. After incubation, the concentration of ethylene in the bottle was measured by a gas chromatograph (GC-14B, Shimadzu) equipped with a flame ionization detector and Porapak N (50/80 mesh; GL Sciences, Tokyo, Japan). The activity was also measured in $\frac{1}{2}$ MS plant growth medium with sucrose at $0.87 \mathrm{~g} / \mathrm{L}$ at different levels of nitrogen as in the MR medium.

\subsection{Effect of Inoculation on Sweet Potato}

The experiment was conducted in a phytotron (LH-240, Nippon Medical \& Chemical Instruments Co., Ltd., Osaka, Japan) with $14 \mathrm{~h}$ light and $28 / 25^{\circ} \mathrm{C}$ day /night temperature with 6000 to 7000 lux light intensity in white florescent light conditions. Each strain was prepared at $10^{9} \mathrm{CFU} / \mathrm{mL}$ in the same way as in ARA and inoculated to sweet potato (variety 'Kokei') tissue culture cuttings. The inoculation experiments were repeated in two different conditions: vermiculite pots and agar tubes.

In the vermiculite pots, two Leonard jars were overlaid, and the top pot was filled with vermiculite and the bottom with liquid $\frac{1}{2}$ MS medium which was connected by a cotton wick to supply the liquid nutrient medium to the top pot. The pot was autoclaved before use. The cut part of the saplings was inoculated by dipping it in the cell suspension, and $1 \mathrm{~mL}$ of suspension was poured on the vermiculite around the plant after transplantation. The experiment was conducted in triplicate and the top of the pots were covered by ventilated $(<0.2 \mathrm{~mm}$ pore size), transparent plastic bags (Sunbag, transparent, Sigma-Aldrich, Tokyo, Japan).

In the agar tube conditions, sweet potato cuttings were inoculated by dipping them in the cell suspension and planted in $1 / 2 \mathrm{MS}$ agar $(1.1 \%)$ medium in the capped glass tube $(12 \mathrm{~cm} \times 2.4 \mathrm{~cm})$. Each experiment was set at least in triplicate.

Growth parameters were recorded after around 1 month. Based on the results of the repeated inoculation experiments, in both the vermiculite pot and agar tube conditions, two of the most potent bacterial strains, Klebsiella sp. Sal 1 and Enterobacter sp. Sal 3, were selected for further studies in nitrogen-limiting conditions $\left(\mathrm{NH}_{4} \mathrm{NO}_{3}\right.$ at $\left.0.12 \mathrm{~g} / \mathrm{L}\right)$.

\subsection{Effect of Inoculation on Tomato}

Tomatoes were selected for further tests because they were the most responsive to different levels of inorganic nitrogen when compared to spinach and carrot (data not presented). In addition, a large number of uniform seedlings could be produced from seeds as compared to sweet potato. Tomato seeds ('Chika' $\mathrm{F}_{1}$ hybrid, Taki Company, Kyoto, Japan) were surface-sterilized by dipping them in $70 \%$ ethanol for $1 \mathrm{~min}$, followed by $1 \% \mathrm{NaOCl}$ for $15 \mathrm{~min}$, then washed 7-8 times with sterilized distilled water. The inoculation experiments were conducted in two different culture conditions, liquid media tubes and Gelrite petri dishes, and the culture conditions were the same as those for the sweet potato experiment.

In the liquid media tubes, one inoculated seed was sown on a piece of single-ply wipe (Kimwipe, wipers S-200) in a capped glass tube $(12 \mathrm{~cm} \times 2.4 \mathrm{~cm})$ containing $6 \mathrm{~mL}$ liquid medium. Growth parameters were recorded after 15 days, and then the concentration of IAA in the culture solution was determined by Prominence Ultrafast Liquid Chromatography (UFLC) System (Shimadzu, Kyoto, Japan) equipped with a photodiode array detector (SPD-M20A) and $100 \mathrm{~L} \times 3.0$ column. The solvent system, $0.5 \%$ formic acid and acetonitrile $(75 / 25 ; v / v)$, was used, and IAA was detected at $278 \mathrm{~nm}$.

In the Gelrite petri dishes, three inoculated seeds were sown on Gelrite $(0.27 \%) \frac{1}{2}$ MS medium in a plastic petri dish $(90 \times 15 \mathrm{~mm})$. Data were recorded 24 days after the seed sowing.

After recording the plant growth parameters, one plant from each treatment was used to check the colonization of the inoculants. The root part was dipped in $50 \mathrm{~mL}$ of sterilized distilled water and gently shaken to suspend the inoculants in the rhizosphere. Then, the root and the stem parts were separated by cutting around $1.5 \mathrm{~cm}$ below the cotyledon, washed in sterilized distilled water to remove most of the surface-attached bacteria, and macerated with $1 \mathrm{~mL}$ of sterilized distilled water using a 
disposable homogenizer (BioMasher, Nippi, Tokyo, Japan). An aliquot of the diluted samples was plated on $\mathrm{N}^{+} \mathrm{MR}$ agar medium, and the appeared colonies were counted after 2 days of incubation at $26{ }^{\circ} \mathrm{C}$. The remaining plants in the petri dish were put in a $30 \mathrm{~mL}$ glass bottle, and ARA was measured as described above.

\subsection{Statistical Analysis}

Statistical analysis was conducted using William's test after MANOVA or Tukey's test after ANOVA.

\section{Results}

\subsection{IAA Production}

Five strains produced IAA in tryptophan-containing, liquid $\mathrm{N}^{+} \mathrm{MR}$ medium (Figure 1). Among them, Klebsiella sp. Sal 1 and Enterobacter sp. Sal 3 produced IAA at the highest levels. These strains produced less IAA in the plant growth medium, and production decreased as the nitrogen levels increased (Figure 2). Klebsiella sp. Sal 1 produced higher IAA at $\mathrm{NH}_{4} \mathrm{NO}_{3}$ levels from 0 to $0.06 \mathrm{~g} / \mathrm{L}$, whereas Enterobacter sp. Sal 3 showed a similar response at a narrower range from 0.015 to $0.03 \mathrm{~g} / \mathrm{L}$.

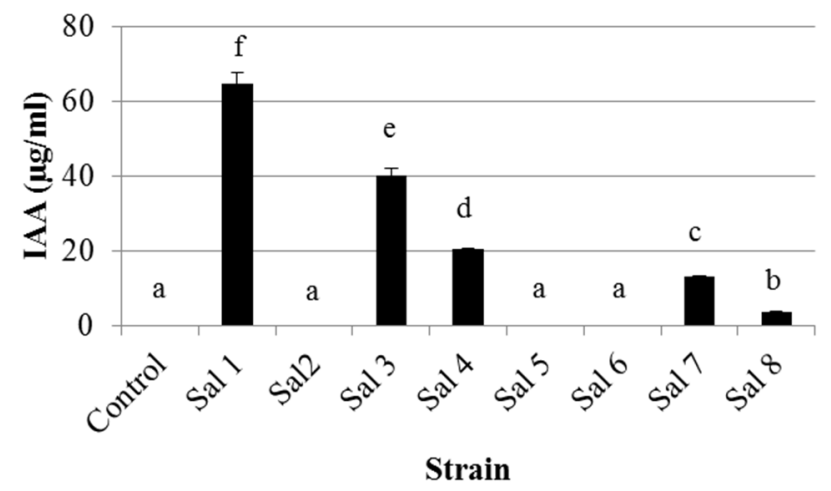

Figure 1. Indole-3-acetic acid (IAA) production by sweet potato endophytes in $\mathrm{N}^{+} \mathrm{MR}$ medium. The bars represent standard deviation $(n=3)$ and different letters indicate significant differences at $P<0.01$ by Tukey's test.
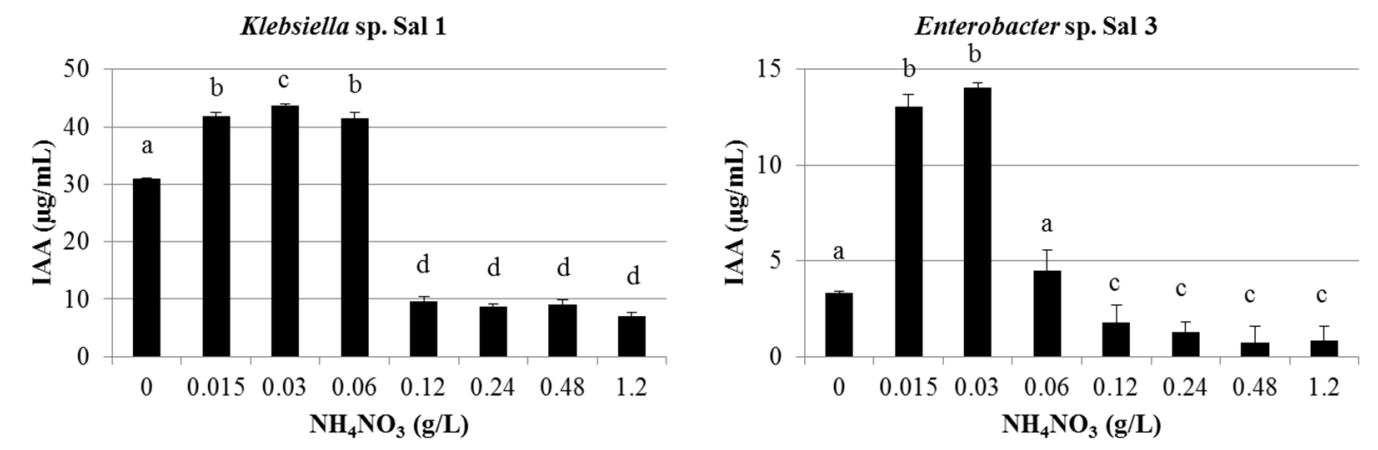

Figure 2. IAA production at different levels of nitrogen in $\frac{1}{2}$ MS liquid medium. The bars represent standard deviation $(n=3)$ and different letters indicate significant differences at $P<0.01$ by Tukey's test. 


\subsection{Nitrogen Fixation Activity}

Klebsiella sp. Sal 1 showed higher nitrogen fixation activity than Herbaspirillum sp. Sal 6 in the MR medium, and in both strains, the activity decreased with an increase in the level of nitrogen in the medium (Figure $3 \mathrm{~A}, \mathrm{~B})$. The activity was lower in the plant growth $\left(\frac{1}{2} \mathrm{MS}\right)$ medium, and a similar trend was observed for the nitrogen level (Figure 3C). No activity was detected for Herbaspirillum sp. Sal 6 in the $\frac{1}{2}$ MS medium at all levels of nitrogen tested.

A. Klebsiella sp. Sal 1

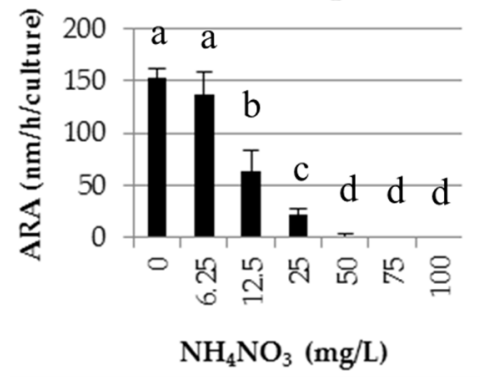

B. Herbaspirillum sp. Sal 6

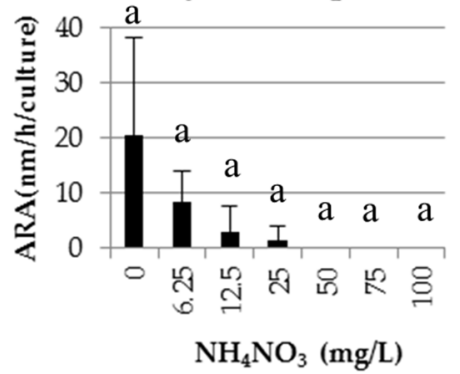

C. Klebsiella sp. Sal 1

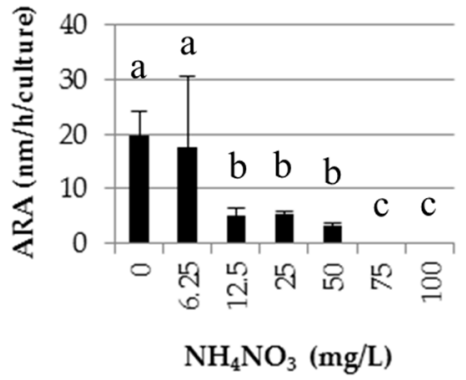

Figure 3. ARA in MR (A,B) and 1/2MS (C) agar medium at different levels of nitrogen. The bars represent standard deviation $(n=3)$ and different letters indicate significant differences at $P<0.01$ by Tukey's test.

\subsection{Effect of Inoculation on Sweet Potato}

Inoculation showed a positive effect on the growth of sweet potato in three different experiments in non-limiting nitrogen conditions (Figure 4). The effects varied some within replications in most of the experiments. In experiment 1 (conducted in the vermiculite pots), inoculation of Enterobacter sp. Sal 3, Stenotrophomonas sp. Sal 5, and Agrobacterium sp. Sal 7 showed a tendency for greater total weight accumulation. Root weights were higher in all of the inoculated plants, and it was highest in Enterobacter sp. Sal 3. The number of roots in the pot experiment showed no clear effects (data not shown). Vine lengths were longer in Enterobacter sp. Sal 3 and Rhizobium sp. Sal 4.

Experiments 2 and 3 were conducted in the agar tube. Because the initial plant size in the agar tubes was smaller than in the vermiculite pots, the root weight and vine length were evaluated and the final fresh weight was used in the case of agar tubes instead of recording the increase in the weight. In both experiments, inoculation showed a positive effect on the increase in total fresh weight, whereas root elongation was not affected (experiment 2) or retarded (experiment 3 ) by most of the strains. Inoculation of Flavobacterium sp. Sal 2 and Enterobacter sp. Sal 3 in experiment 2 and Enterobacter sp. Sal 3, Herbaspirillum sp. Sal 6, and Agrobacterium sp. Sal 7 in experiment 3 induced larger numbers of roots. Overall, Enterobacter sp. Sal 3 repeatedly stimulated the growth of sweet potato.

In nitrogen-limiting conditions, inoculation with the two selected strains showed positive effects on the root number but not on the root weight of sweet potato cultivated in the agar tube (Figure 5). 
Experiment 1 (vermiculite pot)
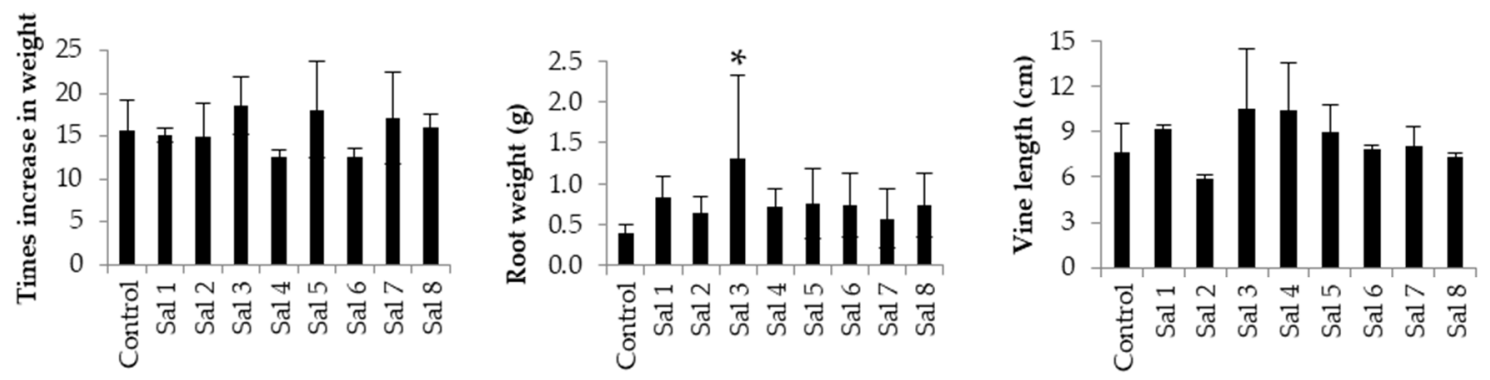

\section{Experiment 2 (agar tube)}
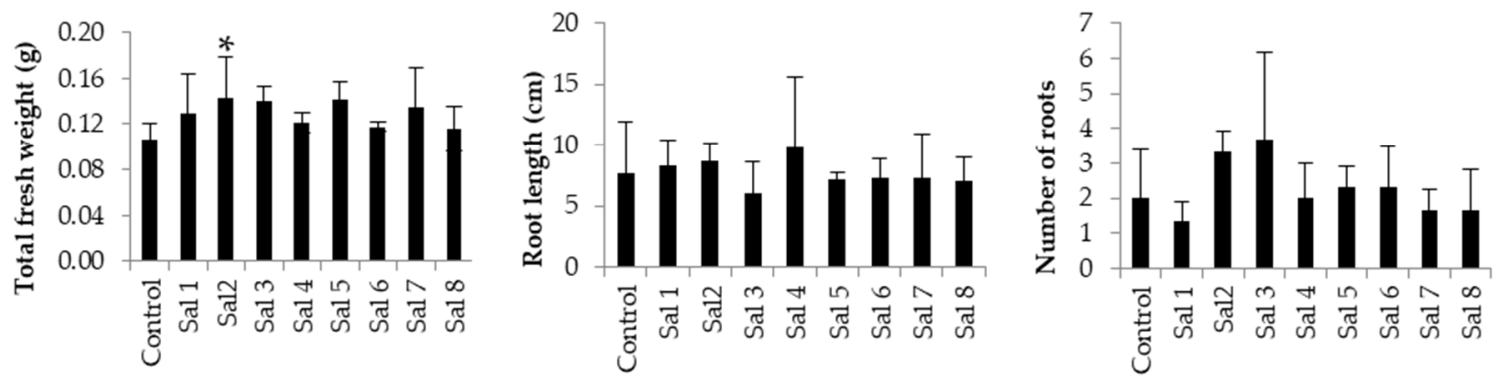

\section{Experiment 3 (agar tube)}
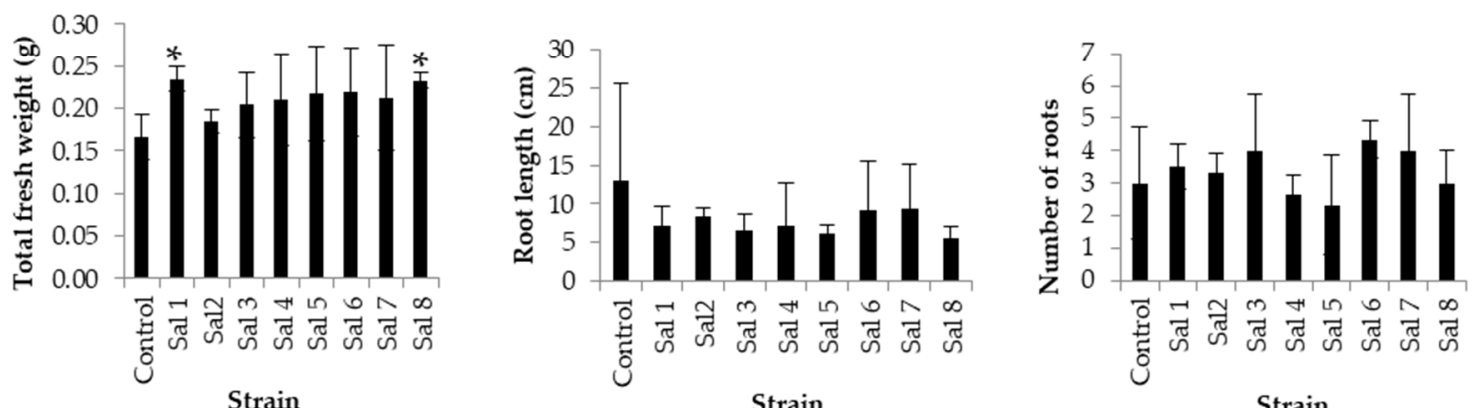

Figure 4. The effect of the inoculation with sweet potato endophytes on sweet potato plant growth in nitrogen non-limiting conditions. The bars represent standard deviation $(n=3)$ and asterisks indicate a significant difference from control at $P<0.05$ by William's test.
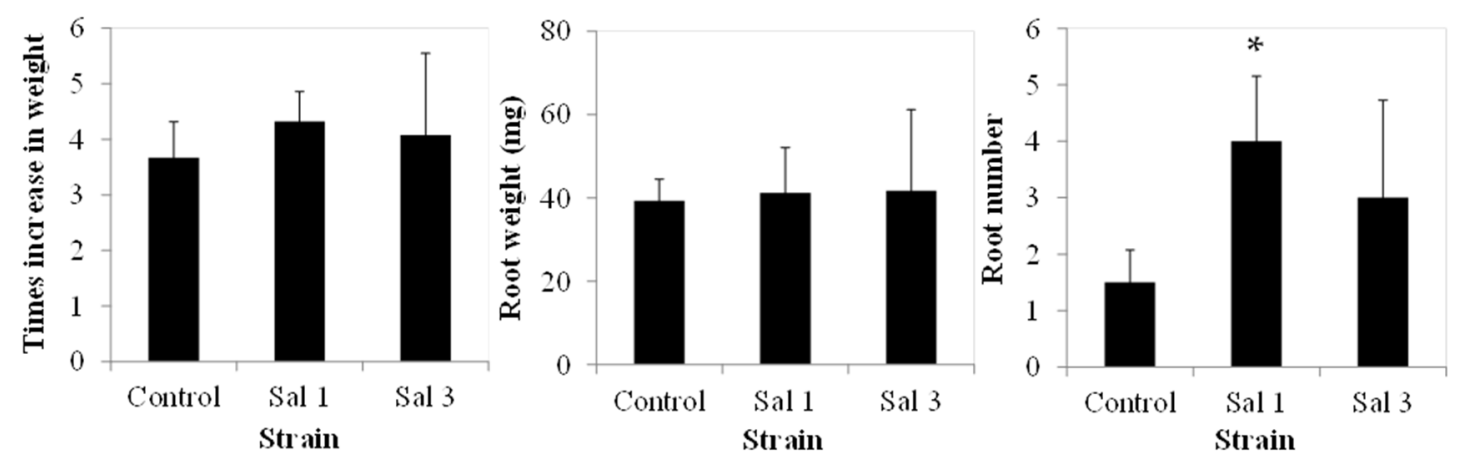

Figure 5. The effect of inoculation with sweet potato endophytes on sweet potato plant growth in nitrogen-limiting conditions in agar tubes. The bars represent standard deviation $(n \geq 3)$ and asterisks indicate a significant difference at $P<0.05$ by Tukey's test. 


\subsection{Effect of Inoculation on Tomatoes}

In vitro tests suggested that the response of tomato seedlings to inoculation with endophytes was related to nitrogen availability. In N-limiting conditions, strains Sal 1 and Sal 3 significantly increased shoot length (Figure 6). In N-depleted conditions, Sal 3 increased root biomass. After the cultivation, IAA was not detected $(<0.1 \mu \mathrm{g} / \mathrm{mL})$ in any of the culture solutions when examined by UFLC.

\section{Experiment 1: Nitrogen-limiting condition}
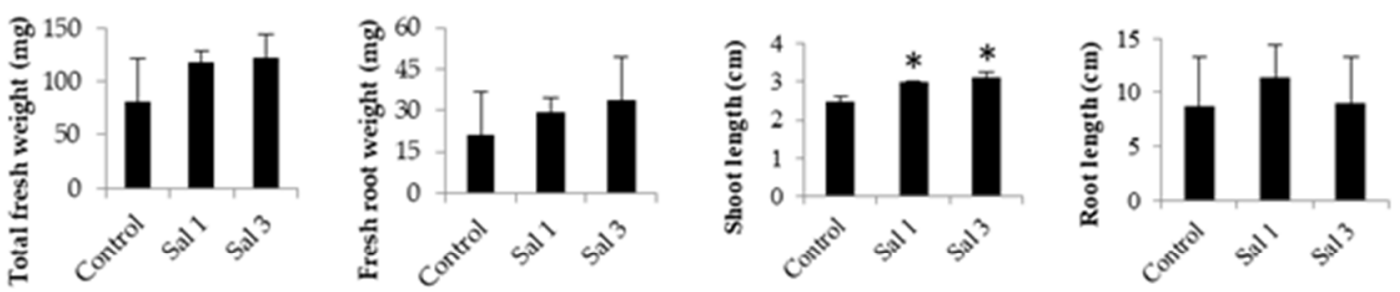

\section{Experiment 2: Nitrogen non-limiting condition}

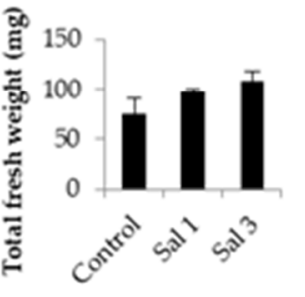

Strain

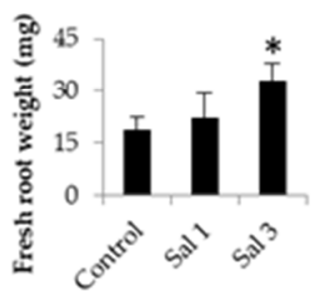

Strain

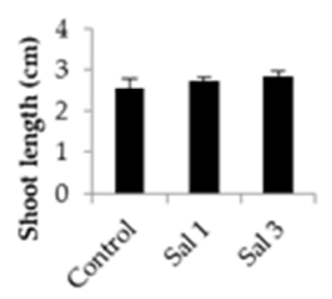

Strain

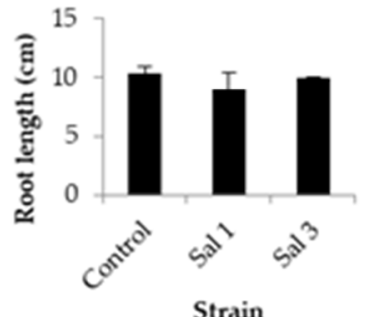

Strain

Figure 6. The effect of inoculation of sweet potato endophytes on the growth of tomato plants in nitrogen-limiting (Experiment 1 ) and non-limiting (Experiment 2) conditions in liquid media tubes. The bars represent standard deviation $(n \geq 3)$ and asterisks indicate a significant difference at $P<0.05$ by Tukey's test.

In nitrogen non-limiting conditions in a petri dish, the effects of the inoculation were apparent in all of the growth parameters (Figure 7). None of the samples showed ARA activity at the end of the cultivation.

Both Klebsiella sp. Sal 1 and Enterobacter sp. Sal 3 colonized tomato plants in large populations (Figure 8). In the liquid test tube condition, internal root colonization rate was higher $\left(2.5-2.6 \times 10^{8}\right.$ and $1.6-2.7 \times 10^{9} \mathrm{CFU} / \mathrm{g}$ fresh weights by Enterobacter sp. Sal 3 and Klebsiella sp. Sal 1, respectively). In the other parts, lower populations at $1.5-3.4 \times 10^{7} \mathrm{CFU} / \mathrm{g}$ and $0.19-6.3 \times 10^{7} \mathrm{CFU} / \mathrm{g}$ fresh weight of stem and leaf were detected, respectively, in both strains. In the rhizosphere, the colonization rate was $0.22-1.3 \times 10^{8} \mathrm{CFU} / \mathrm{g}$ fresh weight.

Under nitrogen non-limiting conditions in a petri dish, colonization in the rhizosphere was higher at $9.5 \times 10^{9}$ and $1.9 \times 10^{11} \mathrm{CFU} / \mathrm{g}$ fresh weight by Klebsiella sp. Sal 1 and Enterobacter sp. Sal 3, respectively. After the rhizosphere, the colonization rate was higher in the root at $3.8-7.5 \times 10^{8}$ $\mathrm{CFU} / \mathrm{g}$ fresh weight, $0.56-1.5 \times 10^{8} \mathrm{CFU} / \mathrm{g}$ in the stem, and $0.16-2.8 \times 10^{8} \mathrm{CFU} / \mathrm{g}$ in the leaf. In both systems, the population of Enterobacter sp. Sal 3 was higher than Klebsiella sp. Sal 1 in many samples, and no bacterial colony was observed in the control plants. 

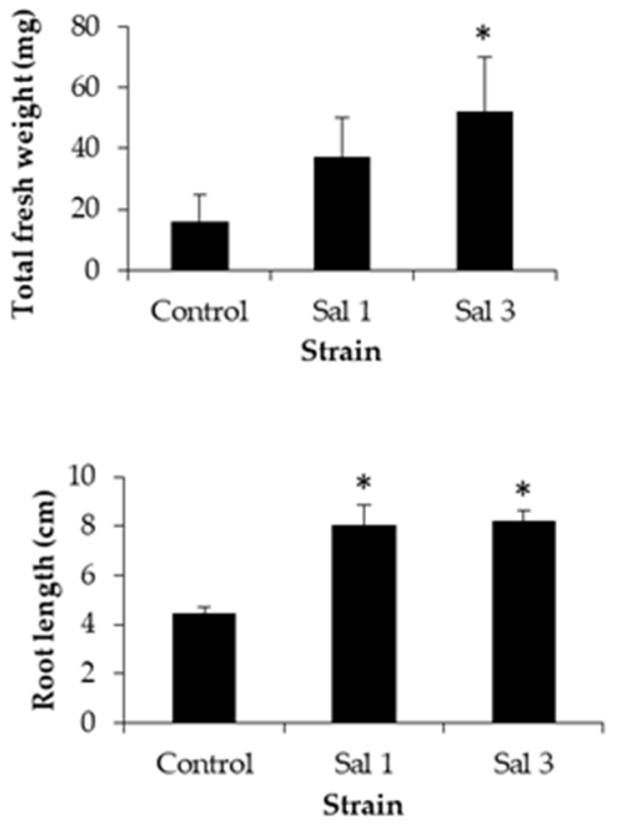
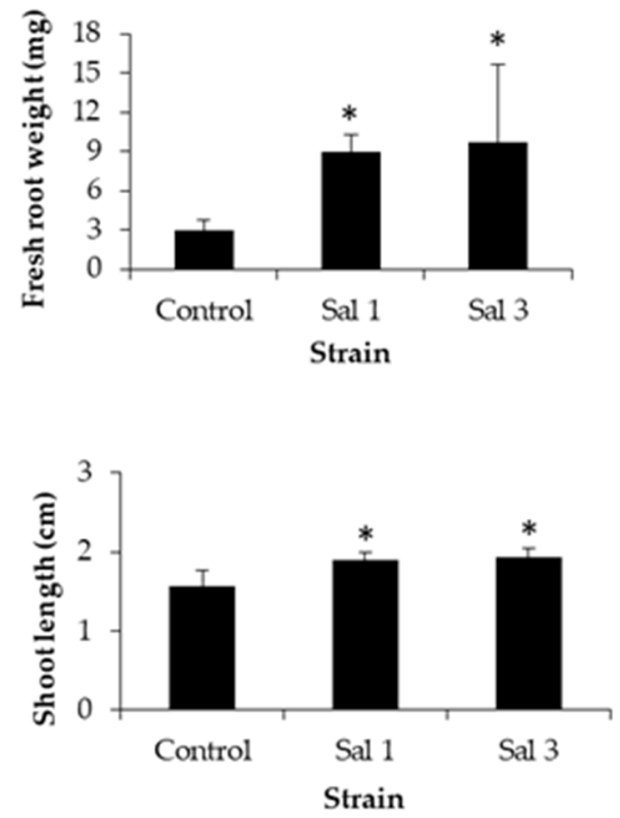

Figure 7. Effect of inoculation of sweet potato endophytes on the growth of tomato in non-limiting nitrogen conditions in Gelrite petri dishes. The bars represent standard deviation $(n=3)$ and asterisks indicate a significant difference at $P<0.05$ by Tukey's test.

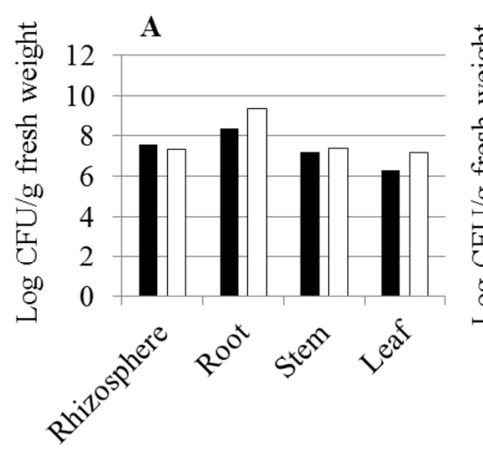

Klebsiella sp. Sal 1

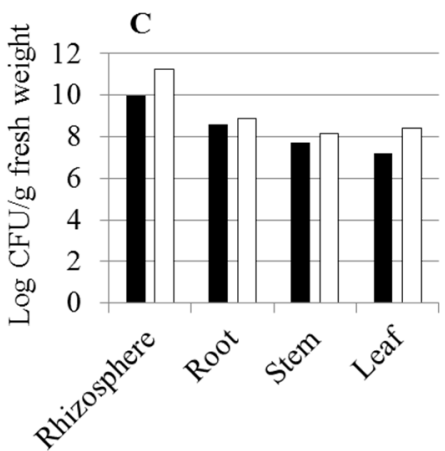

Enterobacter sp. Sal 3

Figure 8. Colonization of the inoculants in tomato plant parts in nitrogen limiting (A) and non-limiting (B) conditions in test tubes and nitrogen non-limiting conditions in petri dishes (C).

\section{Discussion}

In this study, eight endophytic bacterial strains isolated from sweet potato were examined for their growth-promoting activities on inoculated plants. A similar nitrogen-dependent reduction of IAA production was reported in Stenotrophomonas maltophilia [19]. In the nitrogen-free medium, Klebsiella sp. Sal 1 produced a greater amount of IAA compared to Sal 3. Since the strain Sal 1 showed ARA activity, IAA-producing activity seemed to be associated with nitrogen fixation.

The nif $\mathrm{H}$ gene containing strains Klebsiella sp. Sal 1 and Herbaspirillum sp. Sal 6 showed a similar trend of ARA activity in the MR medium, where the activity decreased with a sufficient amount of nitrogen. This property was similar to the response of Herbaspirillum seropedicae Z78 to nitrogen [20].

Earlier reports have shown that plant-associated bacteria can improve plant growth by IAA production [10,21-23] and nitrogen fixation [8]. In this study, bacterial inoculation also showed positive effects on the growth of sweet potato. However, inoculation effects on growth parameters varied among replications due to the difficulty in preparing similar sizes of sweet potato cuttings in the experiments. Even under such varying conditions, most of the inoculants promoted lateral root growth, resulting in greater total root weight. The production of IAA by bacteria in the rhizosphere 
was reported as an important plant growth-promoting factor that stimulates lateral root growth and absorption of nutrients [24]. In this study, the positive effects of the strains Klebsiella sp. Sal 1 and Enterobacter sp. Sal 3 might be the result of their IAA production abilities because a similar change in root morphology was observed after inoculation $[25,26]$.

Sweet potatoes and tomatoes were tested under nitrogen limiting and non-limiting conditions at 0.12 and $1.2 \mathrm{~g} \mathrm{NH}_{4} \mathrm{NO}_{3} / \mathrm{L}$, respectively. IAA production peaked at relatively low nutrient levels. Although the nitrogen levels set in this study were within the inhibitory range for IAA production, it was expected that the high nitrogen levels might decrease the optimum level in the plants and microbial consumption. Because a similar morphological change to that caused by IAA was observed (unpublished data) by the inoculation, and IAA was not detected $(\leq 0.1 \mu \mathrm{g} / \mathrm{mL})$ in the culture solution, it was hypothesized that IAA was produced in the plant at lower nitrogen levels where the high populations of the endophytes colonized. In addition, other mechanisms of plant growth promotion by the endophytes may have occurred including phosphate solubilization [23], 1-aminocyclopropane-1-carboxylate (ACC) deaminase activity [27], siderophore production [28], and production of other plant hormones like gibberellic acid (GA3) [29] and cytokinins [30].

The effect of the inoculants was more apparent in the plants grown on Gelrite petri dishes. Higher colonization of the inoculated strains in the petri dish conditions also suggested microbial participation in plant growth promotion.

Both Klebsiella sp. Sal 1 and Enterobacter sp. Sal 3 colonized the rhizosphere and tissues of tomato when seed was inoculated at higher levels. Their cellullase- and pectinase-producing properties [15] might help them enter into the plant tissue. Hydrolytic enzymes at the infection site leads to cell wall degradation and entry of bacteria such as Rhizobium and Azospirillum strains in white clover [31].

High-colonizing endophytes could be applied as biofertilizers or biocontrol agents [32]. The effects of the sweet potato endophytes on tomato plants in this study suggested that they have the potential to colonize the rhizosphere and plant tissue, and to establish a symbiotic relationship with plants besides sweet potato. Further studies are necessary to confirm their endophytic establishment and plant growth promotion under field conditions where diverse microorganisms already exist. To protect the inoculated strains from competition against indigenous microorganisms, the establishment of the useful endophytes on seeds or seedlings before their planting in field environments is proposed.

Author Contributions: S.A.D. and K.I. conceived and designed the experiments; S.A.D. performed the experiments; R.R.P. isolated and sequenced the bacterial strains used in this study; S.H. helped to conduct the experiment, data recording and analysis; F.A. performed the statistical analysis; S.A.D. wrote the paper with significant contributions from K.I.

Funding: This research received no external funding.

Conflicts of Interest: The authors declare no conflict of interest.

\section{References}

1. Rosenblueth, M.; Martínez-Romero, E. Bacterial endophytes and their interactions with hosts. Am. Phytopathol. Soc. 2006, 19, 827-837. [CrossRef] [PubMed]

2. Ryan, R.P.; Germaine, K.; Franks, A.; Ryan, D.J.; Dowling, D.N. Bacterial endophytes: Recent developments and applications. FEMS Microbiol. Lett. 2008, 278, 1-9. [CrossRef] [PubMed]

3. Gamalero, E.; Glick, B.R. Mechanisms used by plant growth-promoting bacteria. In Bacteria in Agrobiology: Plant Nutrient Management; Maheshwari, D.K.K., Ed.; Springer: Berlin/Heidelberg, Germany, 2011; pp. $17-47$.

4. Gamalero, E.; Glick, B.R. Plant ethylene modulation by beneficial bacteria. Plant Physiol. 2015, 169, 12-22. [CrossRef] [PubMed]

5. Kandel, S.L.; Joubert, P.M.; Doty, S.L. Bacterial endophyte colonization and distribution within plants. Microorganisms 2017, 5, 77. [CrossRef] [PubMed]

6. Hill, W.A.; Dodo, H.; Hahn, S.K.; Mulongoy, K.; Adeyeye, S.O. Sweet potato root and biomass production with and without nitrogen fertilization. Agron. J. 1990, 82, 1120-1122. [CrossRef] 
7. Santoyo, G.; Moreno-Hagelsieb, G.; Orozco-Mosqueda, M.C.; Glick, B.R. Plant growth-promoting bacterial endophytes. Microbiol. Res. 2016, 183, 92-99. [CrossRef]

8. Yonebayashi, K.; Katsumi, N.; Nishi, T.; Okazaki, M. Activation of nitrogen-fixing endophytes is associated with the tuber growth of sweet potato. J. Mass Spectrom. 2014, 3, A0032. [CrossRef]

9. Khan, Z.; Doty, S.L. Characterization of bacterial endophytes of sweet potato plants. Plant Soil 2009, 322, 197-207. [CrossRef]

10. Dawwam, G.E.; Elbeltagy, A.; Emara, H.M.; Abbas, I.H.; Hassan, M.M. Beneficial effect of plant growth promoting bacteria isolated from the roots of potato plant. Ann. Agric. Sci. 2013, 58, 195-201. [CrossRef]

11. Souza, R.; Ambrosini, A.; Passaglia, L.M. Plant growth-promoting bacteria as inoculants in agricultural soils. Genet. Mol. Biol. 2015, 38, 401-419. [CrossRef]

12. Adhikari, D.; Kaneto, M.; Itoh, K.; Suyama, K.; Gaihre, Y.K.; Pokharel, B. Genetic diversity of soybean-nodulating rhizobia in Nepal in relation to climate and soil properties. Plant Soil 2012, 357, 131-145. [CrossRef]

13. Adhikari, D.; Itoh, K.; Suyama, K. Genetic diversity of common bean (Phaseolus vulgaris L.) nodulating rhizobia in Nepal. Plant Soil 2013, 368, 341-353. [CrossRef]

14. Venkatachalam, S.; Gowdaman, V.; Prabagaran, S.R. Culturable and culture-independent bacterial diversity and the prevalence of cold-adapted enzymes from the Himalayan mountain ranges of India and Nepal. Microb. Ecol. 2015, 69, 472-491. [CrossRef] [PubMed]

15. Puri, R.R.; Dangi, S.; Dhungana, S.A.; Itoh, K. Diversity and plant growth promoting ability of culturable endophytic bacteria in Nepalese sweet potato. Adv. Microbiol. 2018, 8, 734-761. [CrossRef]

16. Gordon, S.A.; Weber, R.A. Colorimetric estimation of indoleacetic acid. Plant Physiol. 1951, 26, $192-195$. [CrossRef] [PubMed]

17. Elbeltagy, A.; Nishioka, K.; Sato, T.; Suzuki, H.; Ye, B.; Hamada, T.; Isawa, T.; Mitsui, H.; Minamisawa, K. Endophytic colonization and in planta isolated from wild rice species. Appl. Environ. Microbiol. 2001, 67, 5285-5293. [CrossRef] [PubMed]

18. Murashige, T.; Skoog, F. A revised medium for rapid growth and bioassays with tobacco tissue cultures. J. Plant Physiol. 1962, 15, 473-497. [CrossRef]

19. Othman, R.; Naher, U.A.; Yusoff, S.Z. Effect of urea-N on growth and indoleacetic acid production of Stenotrophomonas maltophilia (Sb16) isolated from rice growing soils in Malaysia. Chil. J. Agric. Res. 2013, 73, 187-192. [CrossRef]

20. Yin, T.T.; Pin, U.L.; Ghazali, A.H. Influence of external nitrogen on nitrogenase enzyme activity and auxin production in Herbaspirillum seropedicae (Z78). Trop. Life Sci. Res. 2015, 26, 101-110.

21. Raut, V.; Shaikh, I.; Naphade, B.; Prasar, K.; Adhapure, N. Plant growth promotion using microbial IAA producers inconjunction with Azolla: A novel approach. Chem. Biol. Technol. Agric. 2017, 4. [CrossRef]

22. Ali, B.; Sabri, A.N.; Ljung, K.; Hasnain, S. Auxin production by plant associated bacteria: Impact on endogenous IAA content and growth of Triticum aestivum L. Lett. Appl. Microbiol. 2009, 48, 542-547. [CrossRef]

23. Dias, A.C.F.; Costa, F.E.C.; Andreote, F.D.; Lacava, P.T.; Teixeira, M.A.; Assumpcao, L.C.; Araujo, W.L.; Azevedo, J.L.; Melo, I.S. Isolation of Micropropagated strawberry endophytic bacteria and assessment of their potential for plant growth promotion. World J. Microbiol. Biotechnol. 2009, 25, 189-195. [CrossRef]

24. Egamberdieva, D. Indole-acetic acid production by root associated bacteria and its role in plant growth and development. In Auxins: Structure, Biosynthesis and Functions; Keller, A.H., Fallon, M.D., Eds.; Nova Science Publishers Inc.: Hauppauge, NY, USA, 2012; pp. 103-122.

25. Haahtela, K.; Laakso, T.; Nurmiaho-Lassila, E.L.; Korhonen, T.K. Effects of inoculation of Poapratensis and Triticumaestivum with root-associated, N2-fixing Klebsiella, Enterobacter and Azospirillum. Plant Soil 1988, 106, 239-248. [CrossRef]

26. Lin, L.; Li, Z.; Hu, C.; Zhang, X.; Chang, S.; Yang, L.; Li, Y.; An, Q. Plant growth-promoting nitrogen-fixing Enterobacteria are in association with sugarcane plants growing in Guangxi, China. Microbes Environ. 2012, 27, 391-398. [CrossRef] [PubMed]

27. Gravel, V.; Antoun, H.; Tweddell, R.J. Growth stimulation and fruit yield improvement of greenhouse tomato plants by inoculation with Pseudomonasputida or Trichodermaatroviride: Possible role of indole acetic acid (IAA). Soil Biol. Biochem. 2007, 39, 1968-1977. [CrossRef] 
28. Sharma, A.; Johri, B.N. Growth promoting influence of siderophore-producing Pseudomonas Strains GRP3A and PRS9 in maize (Zeamays L.) under iron limiting conditions. Microbiol. Res. 2003, 158, 243-248. [CrossRef] [PubMed]

29. Brown, M.E.; Burlingham, S.K. Production of plant growth substances by Azotobacterchroococcum. J. Gen. Microbiol. 1968, 53, 135-144. [CrossRef] [PubMed]

30. Akiyoshi, D.E.; Refier, D.A.; Gordon, M.P. Cytokinin production by Agrobacterium and Pseudomonas spp. J. Bacteriol. 1987, 169, 4242-4248. [CrossRef]

31. Plazinski, J.; Rolfe, B.G. Analysis of the pectolytic activity of Rhizobium and Azospirillum strains isolated Trifoliumrepens. J. Plant Physiol. 1985, 120, 181-187. [CrossRef]

32. Compant, S.; Clement, C.; Sessitsch, A. Plant growth-promoting bacteria in the rhizo- and endosphere of plants: Their role, colonization, mechanisms involved and prospects for utilization. Soil Biol. Biochem. 2010, 42, 669-678. [CrossRef]

(C) 2018 by the authors. Licensee MDPI, Basel, Switzerland. This article is an open access article distributed under the terms and conditions of the Creative Commons Attribution (CC BY) license (http:/ / creativecommons.org/licenses/by/4.0/). 